\title{
Internet usage of English for Academic Purposes courses
}

\author{
HUW JARVIS \\ EFL Section, School of Languages, University of Salford, Salford, UK \\ (e-mail: h.a.jarvis@salford.ac.uk)
}

\begin{abstract}
This paper begins by documenting general usage of the Internet as a tool for delivery of English for Academic Purposes (EAP) courses. It then goes on to illustrate how a number of specific internetbased classroom activities might be integrated onto EAP courses in order to equip non-native speakers with the main skills that they are likely to need when following an academic course at a British university.
\end{abstract}

\section{What is an English for Academic Purposes course?}

Most English for Academic (EAP) courses form an important language provision for Non-Native Speakers (NNS) studying at British Universities. EAP courses can either be 'pre-sessional', where students take the course before they go on to further academic study, or 'in-sessional', where students study whilst already on an academic course. A second distinction in course type is between 'subject-specific EAP' and 'common-core EAP',

“... if it is common-core it will be concerned with general academic language and will focus on study skills; if it is subject-specific it will examine the language features of particular academic disciplines or subjects, e.g. social sciences or economics.” Jordan (1989: 150-51).

The primary purpose, however, of all EAP courses is the same. It is to equip NNS with the language and study skills needed so that they may successfully follow their field of academic study. Traditionally this has meant a syllabus defined primarily in terms of 'discourse functions' such as 'cause and effect', 'description', 'narrative', 'process' etc. and delivered through skills classes such as 'academic writing, speaking, listening and reading'. Project work and study skills usually form additional elements to most courses.

There is also an increasing recognition of the need to include 'Information and Communication Technology' (ICT) training for NNS on EAP courses. This training at its most elementary level takes the form of a first-day orientation session. At its more intensive it is either integrated into other EAP course components or delivered as a compo- 
nent in its own right. What works best, and why, is an area for further investigation but is, however, beyond the scope of this paper. Several years ago the content of ICT training was restricted to language work on the word-processor and perhaps the use of on-line library catalogues. The rapid advances in ICT hardware and software have given birth to the widespread use of the Internet at British universities and this phenomenon has clear implications for EAP courses. Our specific focus here is on the Internet which is viewed as only one of several components of ICT. (Other ICT components would include wordprocessing, spreadsheets and databases, presentation packages, on-line CD ROMS etc.). The use of the term the Internet in the context of this paper refers to two distinct but overlapping areas. Firstly, the World Wide Web (the Web) and secondly, email. The Web is viewed primarily as a resource for information and as a medium for delivering distance and on-line learning. Email is viewed as a medium for sending and receiving messages, these might be via a web-page (e.g. www.hotmail.com) or via an alternative software package specifically dedicated to email (e.g. 'Pegasus Mail or 'Outlook Express').

\section{Delivery of EAP on the Internet}

The use of the Internet in general English has now clearly established itself and its specific role on EAP courses has also been significant. A survey of information technology provisions on pre-sessional EAP summer courses at British universities conducted in 1995 and published in 1997 made a number of observations which illustrate just how much progress has been made. Based on information supplied by 30 members of The British Association of Lecturers in English for Academic Purposes (BALEAP) it was found that email was only "slowly coming of age" and that the Web appeared "to be an underused resource", (Jarvis, 1997a: 47-48). Since then, however, the situation seems to have radically changed. Commenting on English as a Foreign Language (EFL) in general, Eastment (1999) observes, "There is no doubt that the Internet is one of the most exciting technologies and one which will eventually transform the way that teaching and learning of English, and the business of ELT is conducted."

In recent years much has been written about the Internet and its applications in the EFL classroom. Teachers interested in this area now have a number of sources from which to get practical ideas. Windeatt et al. (2000) and Teeler (2000) both provide practitioners with a wide range of 'recipe' type lessons for all levels of language learner. With 'Internet English' (Gitsaki and Taylor, 2000) we see the emergence of an EFL coursebook focusing on the English needed to talk about the Internet and to conduct tasks on the Internet. Essentially this publication is a Web-based conversation course for pre-intermediate and intermediate learners. In EAP there are now widespread discussions about the place of the Internet in our classrooms. The 1999 BALEAP conference held at Leeds University is an excellent indication of the enthusiasm that has been generated. The conference itself was dedicated to 'EAP learning technologies' and no fewer than 16 presenters included at least one of the terms: 'network', 'on-line', 'the Internet', 'the Weblweb-sites' and 'email' in their pre-conference abstracts; even more presenters touched on these issues without actually mentioning them in their abstracts.

One of the challenges practitioners face is to deliver courses, or aspects of courses, through the medium of the Internet. A second and equally important challenge is for EAP courses to reflect the ICT expectations of academic departments, whilst also con- 
tinuing to equip students with the necessary language and study skills.

In terms of the delivery of EAP on the Internet, there have been a number of developments worth highlighting. The use of the WWW for delivering distance-learning EAP programmes has now established itself. Perhaps the most widely discussed example of this is the Multimedia Educational Research into Learning via an Information Network (MERLIN) project http://www.hull.ac.uk/merlin/. A research project begun in 1995 and developed by the Language Institute at the University of Hull and British Telecommunications plc, this project "is exploring the latest communications technology to support interaction and collaboration between groups of remote learners, and between these learners and their tutors." (Marsh et al. 1997:52). Although still evolving, recent assessment has been positive and projects of this type may offer a model for the future delivery of in-sessional (in this case credit-bearing) EAP. Oakey (1999) reports that MERLIN "has brought tangible benefits by simplifying the time-consuming administrative aspects of an EAP module with a large and diverse student body, in a UK university context where student numbers are increasing and classroom contact hours are limited."

Web sites specifically dedicated to EAP teaching have also significantly contributed to supporting NNS in their studies. Students now have a range of sites offering language work and study skills advice. Andy Gillett's web site http://www.uefap.co.uk/ is, in my view, an excellent starting point for EAP students. For each of the four skills, it offers practical advice and suggestions. A comprehensive list of book-based references is included for students who wish to do paper-based follow-up work. In addition, there is an exercise section with general exercises for common-core EAP students and subjectspecific exercises for Business, Law and Science and Technology students. There are numerous other EAP web-sites, many of which are hosted at BALEAP member universities. Warwick University, for example, has a 'Self-Access site' which offers a collection of EAP support materials http://www.warwick.ac.uk/EAP/index2.htm. Reporting on the development of this site Nesi (1998: 116) comments “.... it has attracted unexpectedly large numbers of visitors and favourable comments from EAP learners." One limitation to many EAP sites is their dependence on text. Audio and video downloads for the listening and pronunciation sections are either non-existent or have only recently begun to appear. We are however seeing some exciting developments of this area in general English. John Higgins at Sterling University http://www.stir.ac.uk/departments/humansciences/celt/Listen/index.html, for example, has developed a range of interesting listening skills tasks and 'The Virtual Language Centre (Hong Kong)' http://vlc.polyu.edu.hk/ has an excellent 'Pronunciation section'. We look forward to seeing similar innovative developments in EAP.

Email advising is also beginning to be adopted by EAP providers. Altshul (2001), for example, reports on a pilot project at the University of Salford which indicates that "there is a valuable role for using standard email for language advising, especially when students cannot easily meet the lecturer." Using email to advise students and getting them to submit work electronically is clearly set to become a major development on various EAP courses.

So far, we have briefly discussed the Internet as a tool for the delivery of EAP courses and we have noted a number of developments in this field. Let us now move to the second challenge facing practitioners: the need to reflect the expectations of academic departments. Specifically, what are the expectations of Internet use in academic departments? and how can EAP providers reflect these expectations on their courses within the remit of 
EAP provisions? To date, both these questions have not been systematically addressed across institutions. However, the work of Studman-Badillo and Nesi (2001) does offer some insights into the first question. They surveyed departmental Internet use at Warwick University and found that there was "considerable use of the Internet for study purposes" but that "Departments seemed to assume, however, that students were fairly conversant with the Internet, and did not need a great deal of support to use it effectively." In the absence of further research, it is necessary to make intelligent guesses to answer our two questions. Our guesses might usefully be made in very general terms across academic departments and then applied to common-core EAP. With specific academic departments our answers to these questions may, in some cases at least, be very different. A group of computer scientists, for example, are likely to have different and more demanding expectations from their academic departments than, say, sociology students.

\section{Integrating Internet tasks into the EAP syllabus}

An 'authentic task' can be defined as "an activity which is likely to occur outside or beyond the language classroom" Jarvis (1997b :47). The example tasks documented in this section of the paper are an attempt at such authenticity. They reflect the Internet tasks which students need to perform when on an academic course. The Web tasks also reflect aspects of a traditional EAP 'discourse functions syllabus' (expressing narrative or comparison and contrast etc.). In addition these tasks practise what could be usefully termed 'ICT study skills' such as 'accessing sites', 'evaluating sites' and 'managing information'. The email tasks by contrast represent a shift from the traditional EAP syllabus by introducing a newer notion of 'email writing functions' into the syllabus. Examples of such functions include arranging tutorials or requesting clarification for an assignment, etc.

\subsection{Web-based tasks}

Academic departments are likely to require students to find information on the Web, to evaluate the quality of the information and, if necessary, to use it in their assignments. A first Web EAP lesson can thus be usefully spent on "searching and organising information". Students create several relevant folders one of which is named "Search Engines" - into this folder can go three or four search engine web sites, for example. http://www.yahoo.com, http://www.altavista.com/ and http://www.ask.co.uk/. Other folders, which can be filled in subsequent classes or self-study sessions, might include 'Projects', 'Grammar' etc. Time can be allocated to conducting and refining searches on a given topic - done with more than one search engine web site, students should soon realise that different sites come up with different results. Class time can then be spent focusing on issues related to their searches. Issues such as the search engine 'hits' are no indication of 'quality', nor is the numerical list any true indication of the importance of the site. The whole question of 'credible sources' in academic life can be explored. Here useful questions might include:

- Is the site an on-line refereed journal?

- Is it a recognised newspaper or magazine?

- Is it hosted by an education institution? (A URL address which includes either ....ac... or ...edu...) 
If the answers to the questions above are 'no' then further questions to ask might be:

- What information is provided about the author?

- Has (s)he published elsewhere? Is there a contact email address?

- Are there links to other sites where the answers to the above questions are yes?

- Is the web site coherent and logical?

All these questions cannot provide 'guaranteed assurances' but are nevertheless still worth asking in order to access the likely credibility of the information obtained. From answering questions of this type, students can be given the following general guidelines: 'on-line refereed' journals are 'most credible' and can be used and cited; magazines and newspapers have a similar 'credibility rating' as their paper-based versions or counterparts i.e. 'varied', sites which include WWW ... ac...or WWW...edu... in their URL are from education institutions and should, therefore, be 'reasonably credible', other sites may or may not be credible - but this should not be automatically assumed.

Students can be reminded that anyone can post anything on the Web and the saying that we "should not judge a book by its cover" is probably even truer for web sites. Books stored in university libraries have, at least, been put there for a specific academic purpose! In short, although the vast quantity of information on the Web can be empowering and very useful in academic studies, it needs to be treated with some reservations.

Once students are familiar with accessing information on the Web and are aware of some of the limitations, its potential for EAP can be further exploited. Detailed below is an indication of what can be done within the terms of Web-based activities for the common-core EAP classroom. Our example lesson here takes the discourse function of 'narrative'. Ask students to think of a famous person dead or alive, for example, Princess Diana, Ghandi, Kennedy or Mandela. Students (in pairs, groups or individually) are given an essay title "The life and work of ...." Brainstorm headings under which students will need to find information and make notes. For Princess Diana these headings might include: Life (birth and death); Family (including names of parents, brothers and sisters, date of marriage, names and dates of birth of children; Other important dates in her life; Charities associated with and Other relevant facts. Students conduct searches in order to make notes under the given headings. Make sure students bookmark all information and note what information was taken from which site (this will be vital when students acknowledge references in the final essay). Ask students to download one or two appropriate graphics to include in their essay (again they need to note the reference). When students have found all the information they need, they can begin to organise their essay and work on the first draft.

For essay work of this type it can be useful to adopt a "process genre approach to teaching writing" (Badger and White, 2000). Such an approach seeks to effectively combine the three main perspectives on teaching writing skills. It takes the positive features of a 'product approach' which views writing as being mainly about linguistic knowledge (Pincas, 1982). The approach combines 'product approaches' with the advantages of a 'process approach' which stresses "learning to write in a foreign language because it focuses on the processes or stages a writer goes through in order to complete a coherent piece of written text. Stages such as brainstorming ideas, planning, writing a first draft, editing and revising etc" (Jarvis, 1997c :166). A process genre approach then adds the element of 'genre' 
which focuses on the purpose and context of the text, a vital element to writing academic assignments. Thus, for the essay above, input on the language of 'narrative' is given, input also focuses on essay writing in an academic-context, techniques for paraphrasing texts and the essential need to avoid plagiarism. Input will additionally be needed on how to reference web-site material in the text of the essay and in a bibliography at the end. If thought desirable the whole lesson(s), from notes to final product can be done electronically by asking students to submit work as a word-processed attachment. Again, in the absence of comprehensive research we are left guessing as to which method of submitting an essay is most likely to reflect the expectations of academic departments at most universities. One suspects most tutors still require paper-based essays but this may be slowly changing. For many EAP classes several lessons of input will be needed but the essays themselves can, where necessary, be completed for homework.

It is not difficult to see how other items on an EAP syllabus can be developed with lessons of this type. A second example on 'comparison and contrast' in which students work in pairs to compare and contrast two countries and make notes under headings such as 'size, 'population', 'weather' etc. is more fully discussed in Jarvis (1997b :47-48).

\subsection{Email-based tasks}

Academic departments are likely to expect students to use email in a number of ways. A huge range of 'email writing functions' between student(s) and student(s), and teacher and student(s) can be set up for the EAP classroom. The possibilities for language exploitation will be obvious to all experienced EAP practitioners. Students can be set tasks to arrange meetings (to discuss a group project) with each other or with a tutor or to request an extension or clarification for an assignment etc. Pre-sessional EAP students can additionally be set tasks around the theme of getting help from university services. Such tasks might include:

- Emails to the university computer providers asking any number of questions (about printing facilities, network failures, passwords, etc.)

- Emails to the university accommodation office (about availability of a flat, swapping flats with a friend, prices, etc.)

- Emails to personal tutors (about poor exam results, a personal problem, requesting an appointment, etc.)

- Emails to academic tutors (requesting an extension to an assignment, clarification of a title, suggestions for revision, requesting an appointment, etc.)

- Emails to the International Office (about financial problems, scholarships, etc.)

\section{Conclusion}

The context of this paper and the tasks documented have been specific to EAP. However, it is not difficult to see how the notion of, and rationale for, integrating Internet based teaching might be applied to other EFL courses and indeed to other foreign language programmes. By asking the question, "What will our students need to do with the Internet in the target language?", practitioners can begin to develop tasks to equip them to meet these needs. 
Non-native speakers arrive on EAP courses with a range of computer skills - some are very advanced, others very limited. They also arrive with a range of language abilities it will always be difficult to meet the needs of such a diverse group. However, all students will clearly need to use the Internet in their academic studies and all are on an EAP course in order to develop their language and study skills. Esch and Zähner (2000:13-14) comment that;

The art of designing technological support for language learning then lies in identifying the needs of a given set of learners in specific social and cultural settings, and using the rapidly evolving technologies to support particular learning environments in the most effective way possible.

If practitioners take this point as their starting premise, and view the Internet as a pedagogical tool for delivering specified learning outcomes, then applications such as those detailed in the second part of this paper can be refined and further developed in a positive way on a range of language courses.

\section{Bibliography}

Altshul, L.A. (2001) Language advising by email. In: Mozzon-Mcpherson, M. and Vismans, R. (eds.), Beyond Language Teaching Towards Language Advising. London: CILT.

Badger, R. and White, G. (2000) A process genre approach to teaching writing. ELT Journal, 54 (2): 153-160.

Eastment, D. (1999) The Internet and ELT. The British Council, Summertown Publishing.

Esch, E. and Zähner, C. (2000) The contribution of Information and Communication Technology

(ICT) to language learning environments or the mystery of the secret agent. ReCall, 12 (1): 5-18.

Gitsaki, C. and Taylor, R. P. (2000) Internet English. Hong Kong: Oxford University Press.

Jarvis, H. A. (1997a) The Role of IT in English for Academic Purposes: a survey of provisions on pre-sessional courses at British Universities. ReCall, 9 (1): 43-51.

Jarvis, H. A. (1997b) Using The World Wide Web for an 'authentic learning experience. Modern English Teacher, 6 (4): 45-49.

Jarvis, H. A. (1997c) Word-processing and writing skills: practical applications to language teaching text books. British Journal of Education Technology, 28 (3): 165-175.

Jordan, R. (1989) English for academic purposes (EAP). Language Teaching Journal, 44 (1): 150-51.

Marsh, D., Arnold, I., Ellis, E., Halliwell, J., Hodgins, C. and Malcolm, S. (1997) Project MERLIN A learning environment of the future, $\operatorname{Re} C A L L 9$ (1): 52-54.

Nesi, H. (1998) Using the Internet to teach English for academic purposes. ReCall, 10 (1): 109-117.

Oakey, D. (1999) An EAP module via the Merlin Internet Learning Environment. In: Morrison, B., Cruikshank, D., Gardner, D., James, J. and Keobke, K. (eds.), Information Technology \& Multimedia in English Language Teaching. Hong Kong: English Language Centre, Hong Kong Polytechnic University.

Pincas, A. (1982) Teaching English Writing. London: Macmillan.

Studman-Badillo, B. and Nesi, H. (2001) Internet Use: assumptions and expectations in British universities. In: Howarth, P. and Herington, R. (eds.), EAP Learning Technologies. Leeds: Leeds University Press.

Teeler, D. (2000) How to Use the Internet in ELT. Harlow: Longman.

Windeatt, S., Hardisty, D. and Eastment, D. (2000) The Internet. Oxford: Oxford University Press. 